LEITURAS E RESENHAS 



\section{Revisitando a fala egocêntrica: uma nova hipótese}

[JUNEFELT, Karen. Rethinking egocentric speech: towards a new hypothesis. N.Y.: Nova Science Publishers, 2007. 113 p.]

Karin Quast *

Nesta instigante obra, de interesse àqueles que buscam compreender a aquisição da linguagem pela criança, questões concernentes à fala egocêntrica e à relação pensamento-linguagem, Junefelt traz dados de uma criança cega (Anders) que vinha acompanhando há oito anos. O episódio escolhido para as reflexóes da pesquisadora revolve em torno de uma atividade de elaboração de um conto de fadas por Anders (aqui com oito anos de idade), que é filmado enquanto desenvolve e escreve seu conto, acompanhado apenas de seu constante e inseparável companheiro: o boneco Fredrik.

Porém, enquanto elabora e escreve, Anders dialoga com Fredrik. Alterando seu tom de voz, Anders personifica Fredrik. Realizando, pois, uma análise criteriosa, meticulosa e detalhada desse episódio, Junefelt, a partir da perspectiva bakhtiniana de linguagem, objetiva reabrir a discussão sobre a fala egocêntrica, que tem sido, desde Piaget e Vygotsky, tomada como um estágio no desenvolvimento comunicativo e cognitivo da criança, ainda que de perspectivas diferentes ${ }^{1}$.

Questionando o enfoque primordialmente individualista e monológico nas análises dessa fala - em que o "eu" e o "outro" são considerados em termos de alienação e oposição - , bem como algumas das proposições tanto de Piaget quanto de Vygotsky, Junefelt não somente analisa os dados sob o enfoque dialógico, mas, para pontuar as formulações das quais discorda, realiza um movimento talvez único: efetua primeiramente a análise sob a perspectiva tanto piagetiana como vygotskiana.

Assim, de forma a atingir seus objetivos, a pesquisadora divide o livro em sete capítulos. No primeiro, aponta como a aquisição da linguagem pela crian-

\footnotetext{
* Professora convidada do curso de Especialização em Língua Inglesa da Unitau; doutora em Educação pela Unicamp, Campinas, SP, Brasil.mktostes@uol.com.br

I. No Brasil alguns pesquisadores já questionaram a linearidade discurso social - fala egocêntrica discurso interior, proposta por Vygotsky. Ver, por exemplo, Smolka (1993), Morato (1991), Quast (2009).
} 
ça cega tem sido utilizada como prova para teorias inatistas. Por outro lado, muitas pesquisas consideram a fala egocêntrica da criança cega como um problema terapêutico, estando relacionada a "problemas em dominar as experiências, bem como a dificuldades de compreensão e generalização" ou, ainda, a problemas identitários - diferenciação "eu-tu", construção da auto-imagem ou auto-representação. Sob a perspectiva piagetiana, a fala egocêntrica, por vezes considerada meramente como ecolalia ${ }^{2}$, é tomada como sinal de anormalidade, ou seja, de que a criança ainda não atingiu o estágio da socialização. Essa concepção conduz, conseqüentemente, a suposições problemáticas acerca do que é considerado anormal, em relação tanto à comunicação quanto à cognição da criança cega.

Tais formulaçôes vão sendo colocadas em xeque, observando-se o discurso de Anders. Porém, a densa análise realizada por Junefelt, bem como as conclusões a que chega, deve-se não somente a seu olhar bakhtiniano. Sua investigação longitudinal, da qual vemos aqui apenas um breve momento, não cobre somente eventos que ocorreram no ambiente familiar, mas também na escola, permitindo-lhe uma visão mais abrangente dos contextos, das atividades e dos interlocutores de Anders. É, portanto, essa familiaridade com os variados contextos, atividades e eventos discursivos dos quais Anders participa que lhe permite uma compreensão privilegiada dos dados, não se atendo à superfície visível. Junefelt estabelece, portanto, relações entre contextos, eventos e atividades passadas e que emergem, mesclam-se, são embutidos, nesse episódio. É somente por conhecer a história de Anders que Junefelt pode reconhecer seus interlocutores e os enunciados retomados de eventos anteriores e concebê-los como fala egocêntrica e não ecolalia. É preciso considerar eventos, contextos e situações vivenciadas no passado - e que envolvem atividades e ações levadas a cabo com outras pessoas - e que podem emergir no momento presente. A criança pode estar dialogando com aqueles contextos, aquelas situaçóes, aquelas atividades, aquelas pessoas, que estarão, sim, presentes — não física, mas mentalmente.

No capítulo 2, dedicado à metodologia de pesquisa e de análise dos dados, Junefelt apresenta os dados empíricos; os objetivos da pesquisa; a descrição do sujeito da pesquisa; a escolha da unidade de transcrição e de análise dos dados, visto que, para atingir seus objetivos, é necessário efetuar as análises de uma perspectiva tanto monológica como dialógica. A pesquisadora interroga, pois, se a fala egocêntrica indicaria que a criança ainda não alcançou a idade socializada; apontaria para a não-internalização da linguagem; ou poderia oferecer

2. Junefelt afirma que a fala da criança cega é tão "imitativa" que é por vezes tida como ecolálica ou autística. A pesquisadora, porém, toma essa fala como bi-vocal. 
informações sobre o desenvolvimento lingüístico, comunicativo e cognitivo da criança.

Este capítulo traz, ainda, uma análise mais quantitativa e superficial dos dados, destacando os enunciados considerados monológicos (sob a perspectiva de Piaget e Vygotsky) e dialógicos (sob uma perspectiva não somente bakhtiniana), relacionados a mudança de endereçado (ou destinatário), pergunta-resposta, concordância-discordância, ordem-execução, por exemplo. O diálogo na fala da criança é ilustrado a partir da noção ampla de diálogo de Linell (1998, p. 10), ou seja, como a "interação por meio simbólico por indivíduos mutualmente co-presentes", tomando por base que o "eu" e o "tu" ou o "self" e o "outro" não precisam necessariamente ser indivíduos presentes fisicamente. Tanto aquele que fala como aquele que ouve pode ser o próprio endereçador ou endereçado interior.

No capítulo 3, a pesquisadora traz as formulações de Piaget acerca da fala egocêntrica e analisa seus dados à luz das categorias por ele propostas: ecolalia, monólogo e monólogo a dois ou coletivo. Um dos aspectos questionados por Junefelt é o "outro" ser considerado somente como pessoa física e não como o outro presente psicológica ou mentalmente. A fala de Anders, que se mostra fundamentalmente dialógica, evidencia que a cooperação intelectual e a coordenação de pontos de vista pode também ser realizada com o outro "virtual". Para Junefelt, a presença psicológica do "outro significativo" possui um papel extremamente importante. A fala de Anders também não indica, em momento algum, confusão entre o "eu" e o "não-eu". Anders às vezes age como uma criança sendo corrigida ou estimulada pelo adulto - o boneco trazendo a voz do pai, da mãe, da irmã, da professora, da pesquisadora, bem como seus pontos de vista - e também como o adulto, pois o boneco dirige-se a ele como se Anders fosse o pai (" $p a p p a$ "). Se na superfície visível desse diálogo ouvimos Anders e Fredrik, sob suas "vozes" ouvimos outras vozes, posiçōes enunciativas e papéis sociais sendo desempenhados pelo garoto e pelo boneco e as diferentes relações que se instauram a partir desses papéis. Há, portanto, uma "infusão de outros", afirma Junefelt, e não confusão entre o "eu" e o "não-eu".

No capítulo 4, Junefelt traça percurso semelhante, apontando aspectos na teorização de Vygotsky acerca da fala egocêntrica dos quais discorda. Observa, por exemplo, que, da mesma forma que Piaget, ele não considera o endereçamento nessa fala, o que a leva a questionar algumas formulações em relação à auto-regulação. Enfocando a dialogicidade, Junefelt problematiza, também, a questão da abreviação, além da linearidade fala socializada-fala egocêntrica-linguagem interior.

Vários pontos discutidos nos capítulos 3 e 4 são retomados no capítulo 5, em que Junefelt procede à análise dos dados sob a perspectiva do dialogismo 
bakhtiniano. Buscando salientar a dialogicidade da fala egocêntrica, a pesquisadora vai mostrando, nos enunciados de Anders, o endereçamento, o diálogo e o dialogismo, a multivocalidade, a bivocalidade, o ventriloquismo e, por fim, a linguagem interior.

No capítulo 6, discute a relação fala egocêntrica-pensamento-linguagem interior, refutando, por exemplo, a noção de pensamento egocêntrico de Piaget, bem como a afirmação de Vygotsky de que a fala egocêntrica e a escrita são monológicas. E, por fim, no capítulo 7 , retoma suas reflexões, propondo uma nova hipótese para a fala egocêntrica, considerando-a como a "representação externa de diálogos internos, enraizados em diálogos anteriores e usados para expressar ou esclarecer pensamentos em atividades específicas". Seria, pois, a expressão aberta da linguagem interior, "o jogo dialético entre signos exteriores e interiores", indicando os "diferentes níveis de domínio, onde a apropriação ainda não ocorreu".

Esta obra, portanto, não apresenta somente uma reflexão crítica acerca da fala egocêntrica, mas traz aspectos relacionados à própria constituição da criança cega. Aborda a questão da importância do outro na compreensão e na apropriação do real; questiona noçôes como imitação, ecolalia e pensamento autístico que se atribuem a essas crianças quando sua fala é vista isoladamente, sem que se tracem as relações com experiências anteriores socioculturalmente situadas. Convidamos, então, o leitor, a dialogar com Junefelt, Anders e Fredrik e com eles refletir sobre as críticas de Junefelt, seu olhar sobre esse modo de ser da linguagem, e sobre a hipótese que aqui apresenta.

\section{Referências bibliográficas}

LINELL, P. Approaching dialogue: Talk, interaction and contexts in dialogical perspectives. Amsterdam: John Benjamins, 1998. 330 p.

MORATO. E. M. Das funçôes e do funcionamento da linguagem: um estudo das reflexões de L. S. Vygotsky sobre a "função reguladora da linguagem" e algumas implicações lingüísticocognitivas para a Neurolingüística. Dissertação (Mestrado em Lingüística) — IEL/UNICAMP, Campinas, $1991.165 \mathrm{p}$.

QUAST, K. Discurso interior e o processo de ensino-aprendizagem da lingua estrangeira. Tese (Doutorado em Educação) — FE/UNICAMP, Campinas, 2009.

SMOLKA, A. L. B. A dinâmica discursiva no ato de escrever: relações oralidade-escritura. In: SMOLKA, A. L. B.; GÓES, M. C. R. (Org.). A linguagem e o outro no espaço escolar: Vygotsky e a construção do conhecimento. Campinas, SP: Papirus, 1993. p. 33-62. 177 p. 